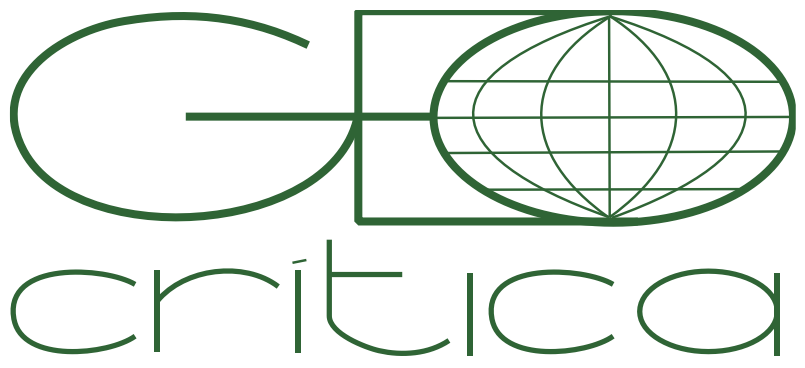

\section{Scripta Nova}

Revista Electrónica de Geografía y Ciencias Sociales

Universitat de Barcelona

Vol. 25, Núm. 1 (2021), p. 239-263

\title{
IDENTIFICACIÓN, LOCALIZACIÓN Y \\ CARACTERIZACIÓN DE LA VULNERABILIDAD \\ ENERGÉTICA A NIVEL DE SECCIÓN CENSAL EN EL MUNICIPIO DE BARCELONA
}

\author{
Lise Desvallees \\ Université de Pau et des pays de l'Adour/E2S UPPA \\ lise.desvallees@univ-pau.fr
}

Recibido: 27 noviembre 2019; Devuelto para correcciones: 6 octubre 2020 ; Aceptado: 4 diciembre 2020

Identificación, localización y caracterización de la vulnerabilidad energética a nivel de sección censal en el municipio de Barcelona (Resumen)

En los últimos años, el interés por la pobreza energética ha emergido en Europa, donde 50 millones de personas encuentran dificultades financieras para calentarse, cocinar o iluminar sus viviendas. En España, la pobreza energética se ha disparado con la crisis económica de 2008, y se ha convertido en un problema público, tratado por políticas públicas a escala europea, nacional y local. Por eso, la elaboración de metodologías de medida del fenómeno es un desafío central, tanto para identificar los hogares necesitando apoyo como por evaluar el éxito de las medidas de atenuación del problema. El presente articulo se inscribe en una dinámica científica de contextualización de la pobreza energética en una escala descentralizada, y aplica el enfoque de la vulnerabilidad energética para captar los factores locales ampliando el riesgo de emergencia del problema. Por eso, el articulo despliega una nueva metodología movilizando los datos de la certificación energética, y la aplica al caso del Municipio de Barcelona a la escala de la sección censal.

Palabras claves: Pobreza energética, vivienda, Barcelona, distribución territorial, sección censal

\section{Identification, location and characterization of energy vulnerability at the census section level in the municipality of Barcelona (Abstract)}

In recent years, interest in energy poverty has emerged in Europe, where 50 million people find it financially difficult to heat, cook or light their homes. In Spain, energy poverty has increased with the economic crisis of 2008, and has become a public problem, dealt with by public policies at European, national and local level. For this reason, the development of methodologies to measure the phenomenon is a central challenge, both to identify households in need of support, and to evaluate the success of measures designed to mitigate the problem. This article is part of a scientific enterprise of contextualization of energy poverty on a decentralized scale, and applies the energy vulnerability approach to capture local factors increasing the risk of emergency of the problem. For this reason, the article deploys a new methodology mobilizing the energy certification data, and applies it to the case of the Municipality of Barcelona at the scale of the census section.

Keywords: Energy Poverty, Dwelling, Barcelona, Territorial Distribution, Census Section 
El concepto de pobreza energética es utilizado para describir y mitigar una forma de pobreza caracterizada por la falta de energía en un hogar, cuando no se puede alcanzar un nivel social y materialmente necesario de servicios domésticos en la energía (Bouzarovski y Petrova 2015). El problema, que afecta a cerca de 50 millones de europeos, ha sido estudiado recientemente en España por un número creciente de estudios e informes procedentes del mundo académico, así como de la sociedad civil. Estos muestran condiciones donde los precios de la energía han subido rápidamente, donde la crisis económica ha tenido impactos importantes, y donde los hogares no están equipados con aparatos y aislamiento que permitan mantener servicios energéticos consumiendo poca energía (ACA 2012, 2014, 2016, 2018).

En paralelo, la pobreza energética se ha convertido en un problema público en España, en la escala nacional con la elaboración de una legislación redefiniendo el alcance de las tarifas sociales, y en la escala de las Comunidades Autónomas, donde cabe destacar el caso de Cataluña. De hecho, en Cataluña se ha puesto en marcha uno de los marcos normativos más avanzados en el mundo, con la normalización de los cortes energéticos por falta de pago en hogares vulnerables por la Ley 24/2015. En este desarrollo jurídico y reglamentario, así como en la mediatización del concepto de pobreza energética, han tenido un papel clave entidades locales procedentes de la sociedad civil y de las administraciones públicas. El Ayuntamiento de Barcelona en particular ha puesto en marcha un esquema de financiación de renovaciones energéticas para hogares vulnerables (Ajuntament de Barcelona 2017), nuevas oficinas urbanas de apoyo de hogares vulnerables-Puntos de Asesoramiento Energéticos (EFE 2018), y ha creado un nuevo operador energético en 2018 cuya misión es proteger a los consumidores contra los cortes de electricidad.

En todas estas escalas de administraciones públicas, unos de los desafíos centrales para la mitigación del fenómeno es su medida. Se trata de un problema multidimensional que no se reduce a la pobreza económica, y que necesita para ser mitigado una identificación contextualizada, teniendo en cuenta la accesibilidad a la energía, la flexibilidad de las viviendas, la eficiencia energética, las necesidades y las prácticas de los hogares (Bouzarovski y Petrova 2015). Sin embargo, los principales indicadores utilizados para medir el problema en España, la Encuesta de Condiciones de Vida (ECV) y la Encuesta de Presupuestos Familiares (EPF), que destacan a España dentro del conjunto de países del Sur de Europa más afectados ${ }^{1}$, no permiten captar

1 El trabajo de la Asociación de Ciencias Ambientales (ACA) basado en las estadísticas nacionales ofrece una primera representación de la pobreza energética en España, presentando un cambio abrupto en las condiciones de vida de los hogares españoles con la crisis de 2008. Dos tipos de indicadores fueron introducidos en su primero informe en 2012, y replicados en los informes de 2016 y 2018 (ACA, 2012, 2016, 2018): 1) un enfoque consensual basado en las percepciones de los hogares procediendo de la encuesta europea ECV, midiendo desde 1994 el nivel de servicios energéticos con preguntas sobre el bienestar térmico, los atrasos en el pago de facturas, y la calidad de la vivienda, 2) un indicador sobre el esfuerzo energético, la parte de los ingresos dedicados al pago de facturas energéticas, recogido por la encuesta nacional sobre los presupuestos familiares. Así, la ACA estima que la ratio de pobreza energética se sitúa entre $10 \%$ y $20 \%$ de la población a nivel nacional. Estos altos niveles de pobreza energética en España corresponden a las pautas geográficas del energy divide, o "abismo energético" separando países 
la naturaleza de la pobreza energética, y ponen en riesgo de fracaso los esfuerzos de mitigación con efectos perversos de exclusión de los pobres energéticos (Sareen et al. 2020). Una información contextualizada tiene que incluir las características de los tejidos urbanos y de la inercia térmica a una escala desagregada como la de los barrios, poniendo en relieve la importante dimensión espacial del fenómeno (Bouzarovski et al. 2017).

En este contexto, el objetivo del artículo es el de proponer una metodología de identificación contextualizada, indirecta y descentralizada de la vulnerabilidad energética. Contextualizada, porque utilizamos fuentes de datos nuevas en la literatura sobre el problema. Se trata del censo de viviendas y la certificación energética, que recogen informaciones detalladas sobre los edificios y permiten elaborar nuevas técnicas de medida cuando se combinan con variables socioeconómicas. Indirecta, porque no intentamos identificar hogares pobres energéticos, sino las características urbanas micro locales que favorecen la emergencia de situaciones de pobreza energética. Esta exposición al riesgo es captada por el concepto de vulnerabilidad energética (Bouzarovski y Petrova 2015), que empleamos como fundamento teórico de nuestro enfoque. El resultado es una metodología robusta para la operacionalización y la cuantificación de la vulnerabilidad a escala suburbana y, por lo tanto, descentralizada.

El artículo está organizado del siguiente modo: en el próximo apartado se exponen los desafíos de la identificación contextualizada y descentralizada de la pobreza energética. El tercer apartado expone las hipótesis que guían la investigación y la metodología utilizada para la creación de la base de datos. El cuarto apartado presenta los resultados obtenidos, analizando la distribución espacial de las variables estimadas. La conclusión reúne los argumentos presentados y formula nuevas preguntas.

\section{Hacia una identificación contextualizada indirecta y descentralizada de la vulnerabilidad energética}

El concepto de vulnerabilidad energética tiene su origen en el Reino Unido en los años 1990, al definir la pobreza energética como la articulación de altos precios de la energía con bajos niveles de ingresos domésticos e ineficiencia energética de los hogares (Boardman 1991). En la década de 2010, varios trabajos elaboran el concepto de vulnerabilidad energética incluyendo factores de riesgo que exceden la escala de los hogares individuales (Bouzarovski 2014; Bouzarovski y Petrova 2015). El carácter político de la definición de los precios de la energía se tuvo asimismo en cuenta, con una reflexión sobre la "accesibilidad" de la energía (la diferencia entre los precios de la energía y los ingresos individuales). La dimensión material del problema fue

del Sur y del Este de Europa - donde las cifras del problema son más altas - de los países del Norte, donde todos los indicadores tienen valores menos elevados (Bouzarovksi y Tirado Herrero 2015). 
ampliada a la geografía de las redes de energía que suministran los hogares y a la historia urbanística y social del desarrollo urbano. Se intentó también captar el carácter social de la privación de energía, considerando las necesidades individuales de consumo como parte de normas sociales y no como el resultado de decisiones individuales. Además, la temporalidad tiene ahora un papel mucho más importante en el concepto de vulnerabilidad, porque se estudia la exposición al riesgo de entrar en una situación de privación de energía, con el objetivo de captar el carácter dinámico del problema. También la flexibilidad del tejido construido es contemplada, dado que la evolución de los hábitos de consumo puede ser más rápida que los cambios de sistemas energéticos existentes, y el desajuste resultante puede convertirse en un peso para los habitantes (Tirado Herrero y Ürge-Vorsatz 2012).

Con estos ejes de investigación, los estudios que aplican el concepto de vulnerabilidad energética enfatizan la dimensión espacial del fenómeno (Bouzarovski et al. 2017). Desarrollan metodologías para cuantificar o estimar el número de hogares vulnerables, y comparten el desafío central de contextualizar esta identificación para superar los límites de indicadores recogidos por las encuestas ECV y EPF que no permiten captar la naturaleza de la vulnerabilidad energética (Sareen et al. 2020). Estos indicadores se concentran en los gastos energéticos y en las percepciones de privaciones, omitiendo datos cruciales como el acceso a la energía de un hogar, la posibilidad de optar por un vector energético, el tipo y la flexibilidad de las viviendas y su localización, y las prácticas cotidianas y sus relaciones con las normas en vigor en una sociedad.

Por eso, inscribimos este artículo en un esfuerzo científico colectivo de desagregación y de contextualización de la medida de la vulnerabilidad energética, participando en trabajos internacionales tanto como en una línea de trabajo española en desarrollo.

\section{Identificación contextualizada de la pobreza energética en Europa: los certificados energéticos}

Aunque las muestras de las encuestas empleadas para la elaboración de indicadores de pobreza energética no permiten desagregar resultados por debajo de la escala de ciudad, existen nuevas fuentes de datos a escalas inferiores. Se trata principalmente de los datos del universo del Big Data recogidos por los Smart meters y los certificados energéticos, que permiten contextualizar la vulnerabilidad energética a escalas descentralizadas. Los primeros abren al universo del consumo individual, tal como se hacía en un trabajo sobre los perfiles de consumo de hogares portugueses (Gouveia y Seixas 2016; Gouveia et al. 2018). Los segundos - el enfoque del presente artículo son una fuente de información sobre las características de las viviendas: su edad, su tamaño, el grado de aislamiento de su evolvente térmica, sus equipos de calefacción del aire y de las aguas...

Cabe destacar que estas metodologías también presentan límites y riesgos ligados a los intereses de sus promotores, y que la transparencia de las fuentes y de los 
algoritmos de cálculo son cruciales. En el caso de los certificados energéticos, también hay que tener en cuenta las críticas dirigidas a los límites del universo de viviendas representadas (no la totalidad de las viviendas, sino las que formaron parte de un proceso de transacción inmobiliaria), y al desajuste entre las normas de eficiencia energética y el consumo real de energía, como pone de relieve una encuesta a agentes inmobiliarios europeos (Pascual Pascuas 2017). Sin embargo, los datos sobre las características físicas de las viviendas y sobre los equipos de consumo de energía permanecen una fuente rica y objetiva de información.

\section{En España: hacia una identificación indirecta de la pobreza energética}

En España existen trabajos que adoptan un enfoque indirecto de la pobreza energética que no estima el número de personas afectadas, sino la exposición de áreas urbanas en las que es más probable encontrar hogares que sufren esta condición por las características de sus poblaciones y de sus tejidos urbanos. Se trataría, por ejemplo, de un estudio de caso en Madrid a la escala de los distritos (Sanz Fernández et al. 2017). Frente a la ausencia de fuentes estadísticas que permitan un análisis distrito a distrito, sus autores se han basado en fichas que incluyen la descripción de los distritos y de los barrios a través de su parque inmobiliario, escogiendo indicadores que se pueden considerar como "factores vinculados con la pobreza energética": el comportamiento térmico de las viviendas, el régimen de tenencia, y datos socioeconómicos de los hogares.

El mismo enfoque indirecto guía dos estudios que exploran la pobreza energética a escala de sección censal en Madrid, y que proponen una simulación de los consumos energéticas necesarios para calentar las viviendas utilizando los datos del censo de viviendas (Martin-Consuegra et al. 2016, 2019). Muestran correlaciones localizadas entre áreas con altas demandas energéticas y áreas económicamente desfavorecidas, pero también la prevalencia de la pobreza energética en hogares pobres independientemente de las características de sus viviendas. Sin embargo, este trabajo no tiene en cuenta otros usos de la energía en el hogar como la calefacción del agua sanitaria, la iluminación, o el aire acondicionado, que en un clima mediterráneo pueden superar el consumo para la calefacción.

\section{Más allá de la pobreza energética: el análisis multivariado a una escala suburbana y descentralizada}

Incluimos en este panorama de la literatura analizada los trabajos que emplean un análisis multivariado a escala de sección censal en ciudades españolas. La unidad censal permite acercarse al mosaico que supone la ciudad, manteniendo un grado de homogeneidad interna debido a su pequeño tamaño, lo que no ocurre en el caso de los barrios (Ocaña Ocaña 2005). Esto es particularmente pertinente cuando se estudia un fenómeno altamente variable como la vulnerabilidad energética. Estudios detallados a nivel de sección censal han analizado los procesos de segregación socioespacial en Barcelona y su aglomeración, utilizando análisis multivariables 
enfocados en la repartición espacial de las clases desfavorecidas (Goñi-Ros 2008) así como de las clases altas (Madariaga et al. 2012).

El presente artículo moviliza estas contribuciones para diseñar una metodología indirecta empleando la rica fuente de datos de la certificación energética.

\section{Metodología}

El articulo tiene por objetivo evaluar la vulnerabilidad energética de las zonas urbanas con el mayor detalle contextual posible, movilizando una reflexión en dos tiempos. El primer tiempo es un enfoque cualitativo basado en los discursos de los actores locales expertos de la vivienda, de la pobreza y del consumo de energía para diseñar hipótesis de investigación. Nos permite incluir en la reflexión los discursos sobre los hábitos de consumo que no son recogidas en las bases de datos, y así nos permite aproximarnos a una visión multidimensional de la vulnerabilidad energética. El segundo tiempo es un enfoque cuantitativo para construir una visión sistémica y geográfica de la vulnerabilidad energética en el municipio de Barcelona.

\section{Elaboración de hipótesis sobre las correlaciones a nivel de sección censal mediante una encuesta cualitativa}

Una primera etapa consistió en la elaboración de hipótesis para guiar la reflexión. Estas se basaron en un estudio llevado a cabo en 2016 sobre la emergencia de la pobreza energética como un nuevo problema social en Cataluña, y cuyos resultados detallados fueron publicados en un artículo dedicado al tema (Desvallées et al. 2020). En el estudio fueron entrevistados actores de la sociedad civil, de los servicios de asistencia social que están en contacto a diario con hogares vulnerables, así como los agentes públicos encargados de diseñar y aplicar políticas públicas de mitigación de la pobreza energética. A partir del análisis de estas entrevistas ${ }^{2}$, e incorporando los resultados de los informes existentes y el seguimiento de la evolución de los precios energéticos en España, se proponen cuatro posibles correlaciones entre los ingresos de los hogares y las características de las viviendas, diseñando factores de vulnerabilidad energética:

1) Correlación de la renta con el régimen de tenencia y con el comportamiento energético de los edificios de vivienda. Fue probado por el informe que analizó la dimensión espacial de la pobreza energética en Madrid (Sanz Fernández et al. 2017), utilizando el periodo de construcción como medida del nivel de confort interior de las viviendas, la normativa técnica de construcción en vigencia siendo indicador del nivel de la temperatura, humedad y calidad del aire. En Madrid, los hogares en pobreza monetaria se concentran en viviendas

\footnotetext{
2 Se utilizó para analizar el corpus de entrevistas transcritas una metodología cualitativa con la aplicación NVivo, que permite descontextualizar los discursos de los actores e identificar temas recurrentes vinculados a los hábitos de consumo de los hogares que son clientes de las administraciones públicas y de las asociaciones de la sociedad civil.
} 
más antiguas y en distritos centrales con mayor porcentaje de tenencia en alquiler. Proponemos probar esta correlación en Barcelona.

2) Correlación de la renta con la presencia de equipos de calefacción y de aire acondicionado, que pueden ser indicadores de riqueza.

3) El precio de la electricidad supera el precio del gas natural. Es posible que una dependencia de la electricidad tenga un impacto sobre las facturas de los hogares, y que los hogares más favorecidos escojan equiparse con gas natural, o comprar y alquilar viviendas con conexión preexistente a la red, dibujando una geografía inversa a los hogares vulnerables.

4) En Barcelona existe una correlación comúnmente admitida por parte de los funcionarios de la administración pública entre los ingresos, la conexión a la red de gas natural, y el uso de butano. Para un funcionario, "el butano se suele asociar a familias con rentas bajas, en todos los barrios, pero se ve especialmente en el centro histórico. Los pisos buenos son los que tienen tuberías para el gas de ciudad, y los malos son los que tienen gas de bombona de butano. En estos últimos suele vivir gente con bajos ingreso".

\section{El análisis de datos: cartografía y análisis multivariable}

El estudio de las pautas de la vulnerabilidad a partir de criterios materiales se ha llevado a cabo mediante la representación cartográfica de los valores relativos de datos proviniendo de tres tipos de fuentes. Después se aplicó un análisis multivariable utilizando el software $\mathrm{R}$ (matriz de correlaciones, análisis factorial y de conglomerados), que tiene en cuenta las siete variables que mejor marcan la eficiencia energética (aislamiento, presencia de aire acondicionado...), las características socioeconómicas (índice compuesto de renta familiar), y las características de las viviendas (edad, régimen de propiedad).

El análisis factorial es una técnica estadística de agrupación de variables que consiste en la reducción de las variables existente, en unas pocas variables de segundo orden, llamadas "componentes", hasta tener el menor error posible. Este análisis se aplica con dos objetivos: uno exploratorio, para descubrir si existe algún patrón en la composición interna de un grupo de variables, y otro para comprobar si los componentes obtenidos son coherentes.

En esta investigación, el análisis factorial ha tenido un carácter mixto en que podría aceptarse cualquier combinación coherente de factores de agrupación, pero que supondría la aparición de factores en relación con la renta, siguiendo las hipótesis de que las características materiales se corresponden con la renta. También se planteó que se formarían agrupaciones poblacionales coherentes, comprobadas mediante un análisis de conglomerados y una representación cartográfica de los valores relativos de datos.

\section{Tres fuentes de datos aplicadas a nivel de sección censal}

La primera fuente proviene del ICAEN que reúne informaciones sobre todas las viviendas vendidas o alquiladas desde 2013, desde el inicio de la campaña nacional de 
certificación energética. El ICAEN certificó 117.222 viviendas en Barcelona con una serie de variables con su geolocalización, que hemos utilizado en una primera fase para situar los certificados en la ciudad con la aplicación QGis. Después hemos hecho coincidir estos puntos con las divisiones administrativas de las 1.061 secciones censales del censo nacional de población y viviendas de 2011 , correspondiendo a zonas pobladas con una media de 2.500 personas. Cada una tiene cerca de 110 certificados, una densidad que permite una comparación sin secciones vacías. La tercera fase fue el cálculo del porcentaje entre el total de los certificados y el número de certificados, presentando cada una de las características energéticas listadas a continuación. La cifra final es una proporción que permite una comparación entre las secciones de las variables siguientes (el detalle figura en el anexo):

- La presencia o ausencia de aislamiento. Una vivienda es considerada como aislada si sus paredes o su techo incluyen una capa aislante.

- La presencia de equipos de agua caliente sanitaria, de calefacción o de aire acondicionado.

- Los vectores energéticos de estos equipos térmicos incluyen los tres vectores energéticos dominantes (electricidad, gas natural, butano o propano), y tres otros poco comunes (solar, biomasa y gasoil). Para no sesgar los resultados - el análisis multivariable da un peso más importante a los casos aislados - solo mantuvimos los primeros en el cálculo.

La segunda fuente es el índice de renta familiar de los barrios, un indicador teórico elaborado anualmente por la oficina técnica de la programación del Ayuntamiento de Barcelona, combinando cuatro variables ponderadas ${ }^{3}$. Los 73 barrios del municipio reciben un valor alrededor de una media de 100. En 2015, el indicador varía entre 34 para los barrios más vulnerables, y 251 para los más favorecidos. Hemos transferido estos datos a las secciones censales correspondientes.

La tercera fuente proviene del último censo nacional de población y viviendas de 2011 , recogiendo a nivel de sección censal el total de viviendas, y el número de alquileres que hemos convertido en un porcentaje. El censo identifica también con precisión la edad de las viviendas a nivel de distritos, que hemos transferido a las secciones censales. Elegimos conservar los periodos de construcción más diferentes: viviendas construidas antes de 1940 o después de la adopción de la primera normativa sobre la eficiencia energética en 1980, que representan el $40 \%$ del parque de viviendas de Barcelona.

3 El modelo micromunicipal se construye a partir de los cálculos de las macromagnitudes de la Renta Familiar Bruta Disponible y de la Renta Familiar Bruta Disponible per cápita elaborados por el Idescat. Las variables combinadas son (1) el nivel de estudio de la población (2) la situación laboral (3) las características del parque de turismo y (4) los precios del mercado residencial (Ajuntament de Barcelona, 2020). 


\section{La distribución espacial de la vulnerabilidad energética en el municipio de Barcelona}

El análisis factorial agrupa las secciones censales más parecidas de manera que se minimiza el error de asignación, formando conglomerados jerárquicos y agrupando las secciones censales por tipos. Los resultados de esta agrupación son relevantes, porque validan los grandes ejes de las hipótesis iniciales, pero también permiten afinar los resultados, matizando algunos de sus aspectos y aproximándose a la complexidad del tejido urbano.

\section{Análisis descriptivo: distribución geográfica de las variables}

En este análisis, comparamos las distribuciones geográficas de seis de las siete variables escogidas ${ }^{4}$, principalmente procedentes de la certificación energética, lo cual constituye la contribución del artículo.

\section{Variable I - Distribución espacial de la renta}

La geografía de la renta familiar ha sido estudiada por numerosos trabajos incluso a nivel de sección censal (Goñi-Ro 2008; Rubiales Pérez et al. 2012): el municipio de Barcelona presenta una desigualdad en la distribución espacial de la renta bien documentada en la literatura.

El índice de renta familiar en la Figura 1 refleja estas observaciones en los barrios periféricos (Goñi-Ros 2008): en los polígonos de vivienda construidos durante los años 1960 y 1970 en los distritos de Nou Barris, Sant Andreu y Sants-Montjuïc, la población residente se caracteriza por un índice de renta muy bajo comparado con el promedio municipal. El índice de renta bajo en barrios más centrales, corresponden en el análisis de Bernat Goñi-Ros a secciones censales con características sociodemográficas muy heterogéneas, con una mayor proporción de personas de nacionalidad extranjera, y elevados porcentajes de categorías profesionales menos cualificadas, así como de más cualificadas (Goñi-Ros 2008). La dinámica de gentrificación de estos barrios, ya identificada en 2008, se ha amplificado, como muestra un estudio sobre los patrones espaciales de la segregación residencial de los grupos altos (Rubiales Perez 2012). Estas pautas corresponden al centro histórico, a la intervención puntual que constituyó la Vila Olímpica, y se añaden a una geografía histórica correspondiendo al extremo sur occidental que marca la Diagonal (San Gervasi, Sarriá, Les Corts), en torno al paseo de Gracia.

\footnotetext{
4 No incluimos la variable de la edad de los edificios, el tema ha sido ampliamente tratado en una serie de estudios sobre la morfología urbana del municipio de Barcelona notablemente en los trabajos del Laboratorio de Urbanismo de Barcelona.
} 


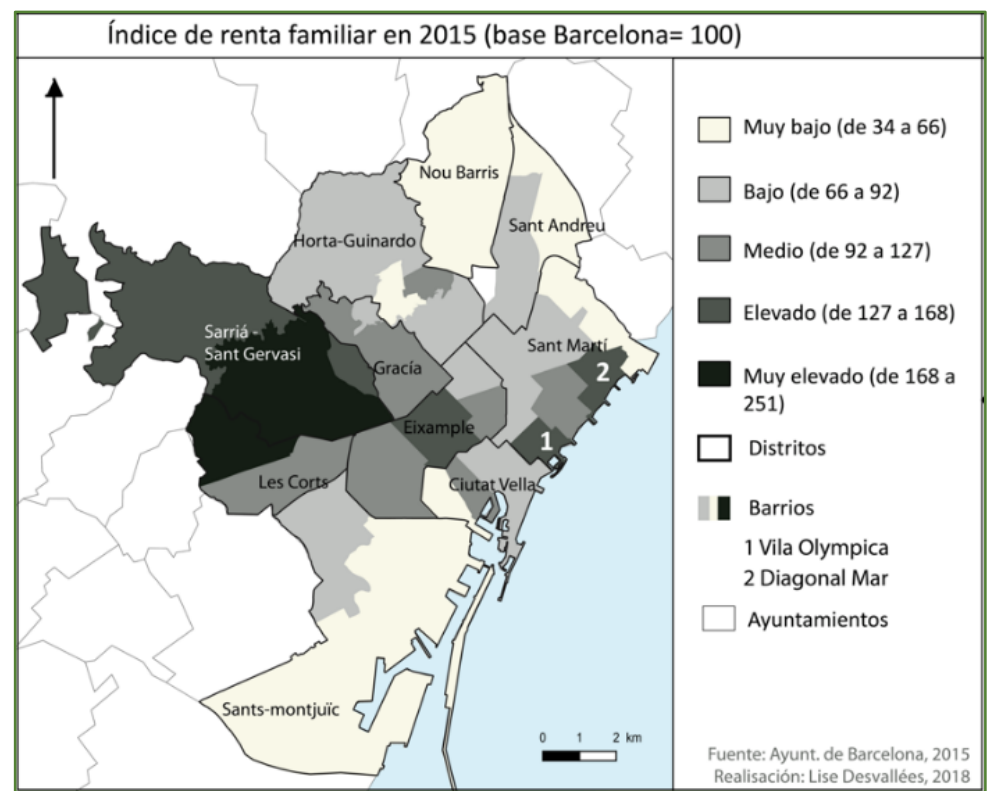

Figura 1. Distribución espacial de la renta familiar en el municipio de Barcelona

Estas pautas sirven de base para analizar la repartición espacial de las características energéticas recogidas por los certificados de energía.

\section{Variable 2 - El aislamiento}

La Figura 2 representa el porcentaje de viviendas certificadas aisladas y muestra altos niveles de aislamiento en el barrio de Sant Martí, correspondiendo a los grandes proyectos urbanos llevados por el Ayuntamiento de Barcelona desde los años 1980. El distrito de Sant Andreu también presenta esta característica, debida a una de las más amplias operaciones de renovación urbana en España: el gran complejo inmobiliario construido en el inicio de la década 2000 alrededor de la antigua zona industrial de la estación de ferrocarriles de Sant Andreu Comtal (Rowe and Ye kan 2014).

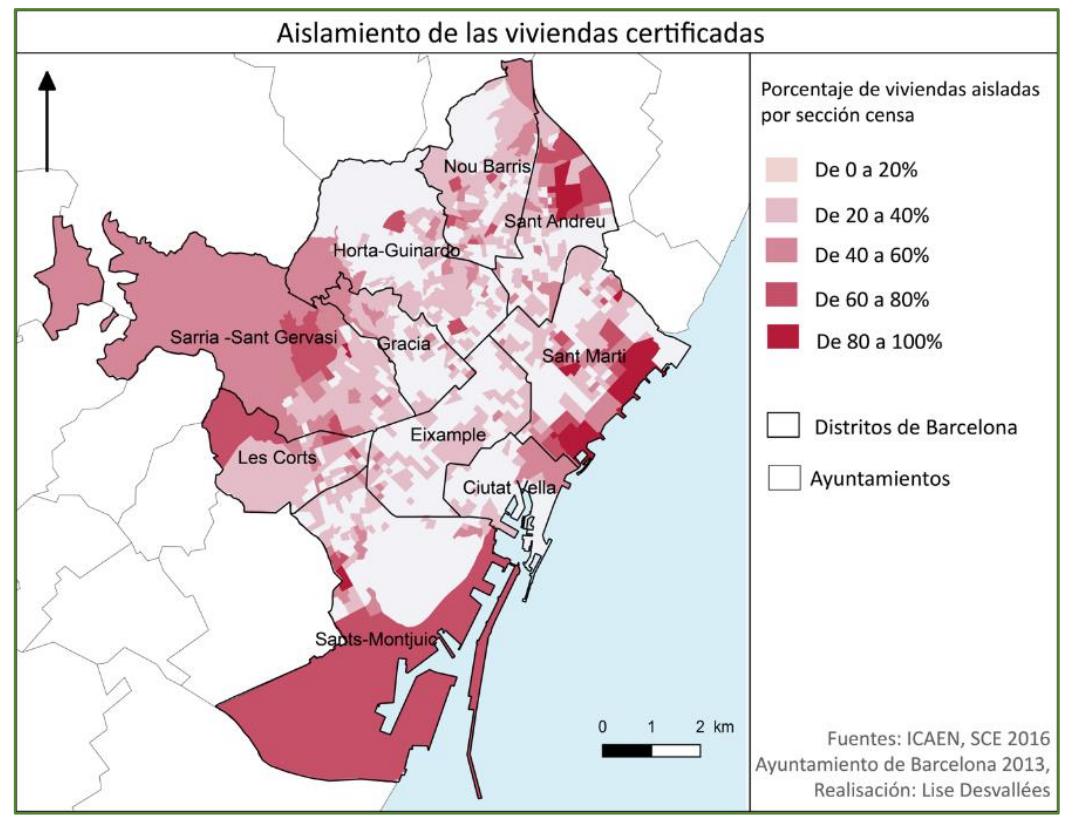

Figura 2. Pautas del aislamiento en el Municipio de Barcelona 


\section{Variable 3 y 4 - Los equipos de calefacción y aire acondicionado}

Las pautas geográficas de los equipos térmicos representadas en la Figura 3 muestran similitudes con las del aislamiento. La presencia de calefacción y la ausencia de climatización representan patrones espaciales invertidos: diseñan un eje central a ambos lados de la Diagonal donde las tasas de equipos son más elevadas. La mayoría de las viviendas certificadas en los distritos acomodados de Sarriá, del centro del Eixample y de la zona del Front Marítim disponen de equipos de calefacción y de climatización. Los distritos más vulnerables de Nou Barris, de Horta-Guinardó y de Sants-Montjuïc presentan valores inversos. Esta relación es interesante y permite diseñar una geografía de la ausencia de equipos de calefacción y de aire acondicionado que se sobrepone a la de las desigualdades socioeconómicas.

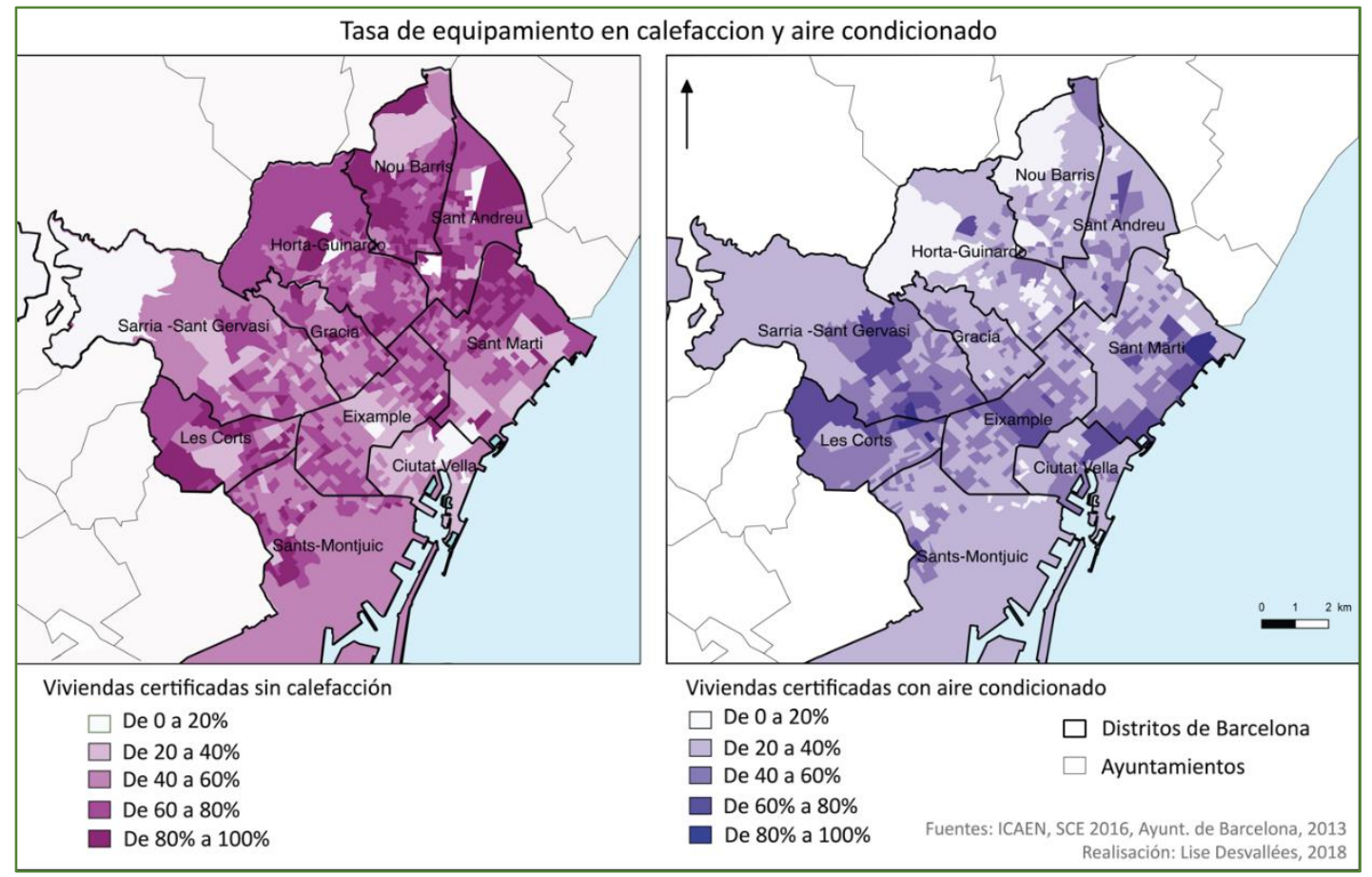

Figura 3. Pautas de la presencia de equipos en el Municipio de Barcelona

\section{Variable 5 y 6 - Las fuentes de energía en los equipos de calefacción y de agua caliente sanitaria}

La Figura 4 pone de relieve el predominio del gas natural en los distritos de Sant Andreu, de Nou Barris, y de Sant Martí al Norte del municipio, y en los barrios de Les Corts y de Sants Montjuïc al Sur. Esta geografía se corresponde con el desarrollo histórico del gas natural en la ciudad - que fue la primera gran red de España (ICAEN 1989, 61). Los primeros barrios conectados a la red en su fase inicial de despliegue entre 1970 y 1974 se encuentran en un círculo que corresponde a las periferias del municipio. La red parte de la planta de regasificación en la Zona Franca de SantsMontjuïc, rodea el municipio y termina en un conducto submarino. 
De modo inverso, las secciones censales del centro del municipio disponen de menos conexiones a la red de gas natural. Los distritos de Ciutat Vella y el centro del Eixample se caracterizan por una densidad de pisos antiguos, estrechos y altos, complicando su conexión a la red, de ahí un mayor predominio de equipos de calefacción del agua sanitaria. En particular, en el barrio de la Barceloneta en el distrito de Ciutat Vella, apenas el $20 \%$ de las viviendas certificadas disponen de gas natural.

Una primera constatación sobre estas pautas es que no parece corresponder a la repartición de la renta familiar. Sigue una lógica de centro-periferias, mientras que la geografía de los ingresos diseña un eje conectando el sector occidental, desde el Valle de Llobregat, con el oriental, hasta la operación urbana del Front Marítim.

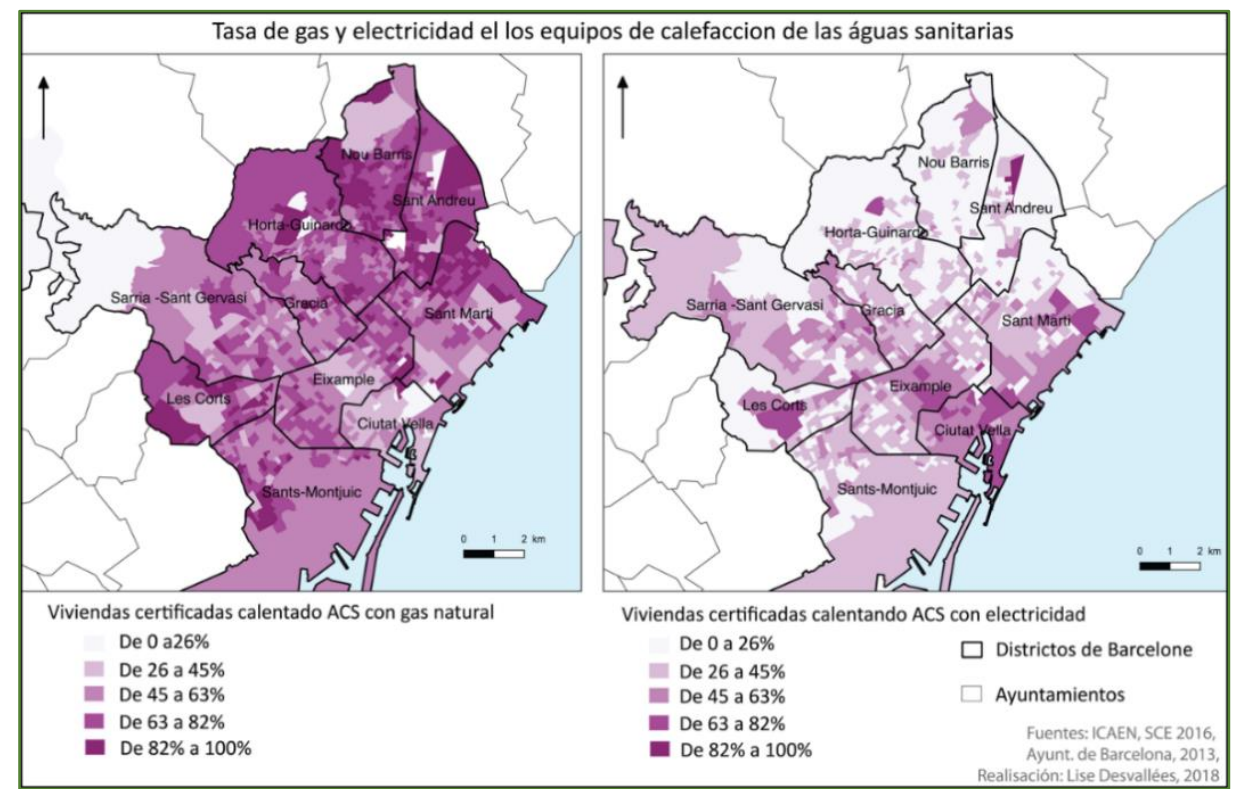

Figura 4. Pautas de distribución del gas natural y de la electricidad para calentar el agua sanitaria

La representación cartográfica de la variable del uso de butano valida la correlación existente comúnmente admitida por parte de los funcionarios de la administración pública entre el nivel de ingresos y el uso de bombonas de butano. Aunque menos generalizado que el gas natural o la electricidad, este vector está más presente en los distritos de Horta Guinardó y de Nou Barris, con una geografía que se corresponde con las variaciones orográficas de la ciudad - las mayores densidades de butano corresponden a zonas urbanas situadas a más de 250 metros de altura - y a morfologías urbanas caracterizadas por casas individuales en gran medida autoconstruidas en las márgenes de la ciudad en los años 1960 y 1970. 


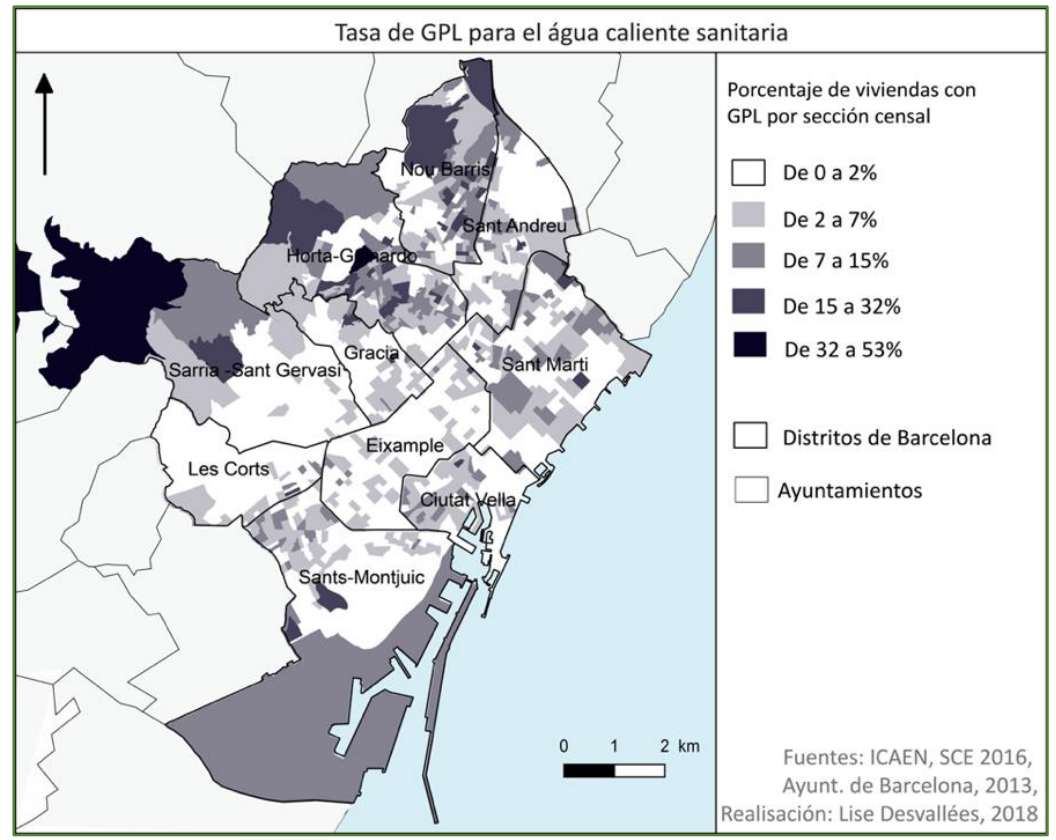

Figura 5. Pautas de distribución del butano

\section{Análisis exploratorio de la interrelación de las variables}

Un primer análisis que precede el enfoque factorial es la siguiente matriz de correlaciones (Figura 6), que representa los coeficientes de correlación entre cada modalidad de las siete variables y las otras, calculadas y figuradas en un gráfico.

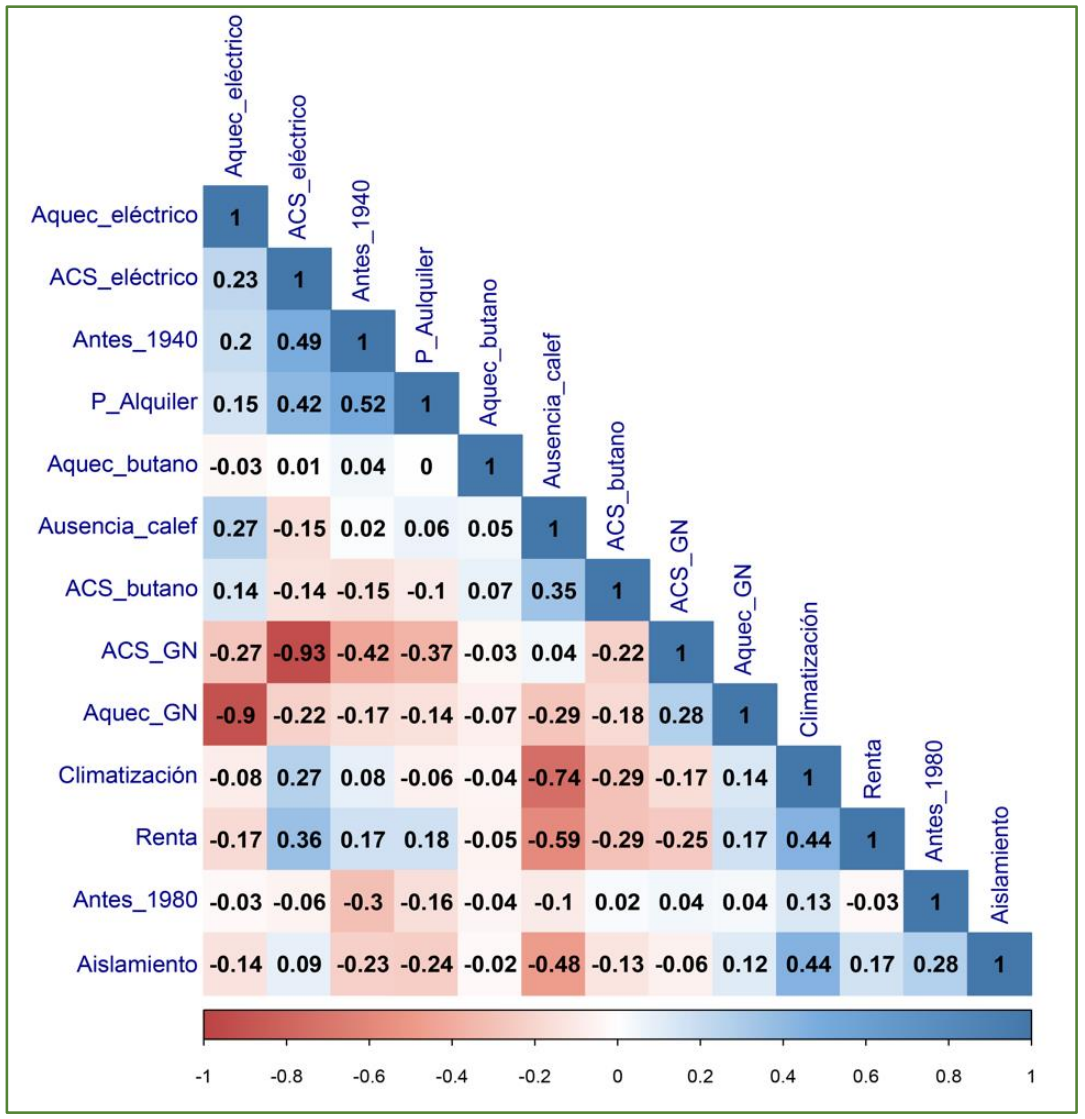

Figura 6. Matriz de correlaciones 
El grafico pone de relieve tres correlaciones más significativas, apareciendo en colores más intensos, en tonos rojos cuando son negativas, y azul cuando son positivas. Una primera correlación aparece entre la renta familiar y la presencia de climatización $(0,44)$, y de calefacción $(-0,59)$. Esta presencia se correlaciona positivamente con medidas de aislamiento $(0,44)$, que aparecen a su vez correlacionados con la presencia de equipos de calefacción $(-0,74)$. Este resultado no aparecía en las correlaciones hipotéticas elaboradas mediante la encuesta cualitativa, posiblemente a causa de su simplicidad: hogares más favorecidos disponen de más recursos para equiparse con equipos de confort térmico.

Una segunda correlación se deja ver entre los vectores energéticos. Las secciones censales donde los equipos de calefacción del agua sanitaria utilizan gas natural son distintas de las secciones donde se utiliza electricidad $(0,93)$, una relación comparable con la de la calefacción. Es decir, que las viviendas más cercanas tienden a utilizar las mismas fuentes de energía. Si este resultado también no hace parte de las correlaciones hipotéticas, puede ser el resultado de la dificultad por los actores entrevistados de elaborar una visión geográfica de las fuentes de energía doméstica en el tejido urbano.

Una tercera correlación significativa es negativa, e implica el uso de butano. Cuantas más viviendas se calientan con esta fuente de energía en una sección censal, menos viviendas están equipadas con aislamiento y equipos de climatización. Asociado con la correlación precedente, este resultado refuerza la correlación hipotética entre los ingresos, la conexión a la red de gas natural, y el uso de butano

La cuarta correlación aparece entre las fuentes de energía, la edad de las viviendas y el régimen de ocupación. En cuanto sube el porcentaje de viviendas antiguas en las secciones censales, sube también la proporción de viviendas alquiladas $(0,52)$, y la presencia de calderas eléctricas. Esta relación confirma los resultados del estudio que mide la pobreza energética a nivel infra urbano en Madrid (Sanz Fernández et al. 2017). También cuadra con los trabajos sobre la segregación socioespacial en Barcelona, mostrando la correlación estrecha existente entre la antigüedad del parque construido y el mercado del alquiler (Bayona y Carrasco 2007). En un contexto de predominio del régimen de propietario ocupante $(75 \%$ de las viviendas), y de lenta renovación del parque, el acceso a la propiedad es espacialmente selectivo. Las viviendas alquiladas son más antiguas y están más deterioradas que la media, y son menos atractivas. En este tipo de bienes inmuebles, las calderas eléctricas representan una inversión barata para los propietarios. Tres de las correlaciones hipotéticas iniciales entre la renta y el régimen de tenencia, el equipo de calefacción, y las fuentes de energía se encuentran reforzadas. Este resultado también alienta a superar el enfoque bi-variado resultando de las encuestas cualitativas, y considerar la interconexión de las variables.

Si esta primera fase permite consolidar las hipótesis llevadas por los ejecutivos del Ayuntamiento, la segunda fase del análisis se dedica a precisar estas correlaciones mediante análisis factorial. 


\section{Análisis multivariable (factorial y conglomerados)}

Continuando el estudio de las correlaciones, se han llevado a cabo análisis factoriales y de conglomerados a escala de secciones censales.

\section{Análisis factorial}

El análisis factorial sobre las trece variables y las 1.061 secciones censales del municipio de Barcelona llega a explicar el 75\% de la información ${ }^{5}$ empleando cinco componentes que son, además, coherentes. El componente 1 explica $24 \%$ de la varianza y sería el que caracteriza los vectores energéticos: correlaciones altas entre la presencia de gas natural en los usos térmicos, y correlación negativa con los equipos eléctricos, la edad de los edificios, y la proporción de alquileres. El componente 2 explica $22 \%$ de la varianza y corresponde al grado de equipos en las viviendas, oponiendo secciones con calefacción, climatización, y altas rentas, y secciones sin equipos y con rentas inferiores. El componente 3 corresponde a $13 \%$ de la varianza y se asocia positivamente con la edad de los edificios y la presencia de aislamiento. Los componentes 4 y 5 suman $16 \%$ de la varianza, y permiten interpretar las variables del uso doméstico del butano, oponiendo secciones censales donde el gas natural es mayoritario con secciones donde es minoritario.

\begin{tabular}{|l|l|l|l|l|l|}
\hline & 1 Componente & 2 Componente & 3 Componente & 4 Componente & 5 Componente \\
\hline ANTES_1940 & $\mathbf{0 , 6 5}$ & $-0,27$ & $\mathbf{0 , 4 0}$ & $-0,11$ & $-0,07$ \\
\hline DESPUÉS_1980 & $-0,14$ & 0,25 & $\mathbf{- 0 , 5 4}$ & 0,19 & 0,24 \\
\hline AISLAMIENTO & 0,10 & $\mathbf{0 , 5 8}$ & $\mathbf{- 0 , 5 2}$ & 0,10 & $-0,05$ \\
\hline CLIMATIZACIÓN & 0,44 & $\mathbf{0 , 6 6}$ & $-0,25$ & $-0,15$ & $-0,12$ \\
\hline AUSENCIA_AQUECIMENTO & $-0,35$ & $\mathbf{- 0 , 8 0}$ & 0,11 & 0,13 & 0,12 \\
\hline ACS_ELÉCTRICO & $\mathbf{0 , 9 0}$ & $-0,08$ & $-0,06$ & 0,24 & 0,10 \\
\hline ACS_GN & $\mathbf{- 0 , 8 1}$ & 0,22 & 0,17 & $-0,45$ & $-0,13$ \\
\hline ACS_BUTANO & $-0,21$ & $-0,44$ & $-0,28$ & $\mathbf{0 , 6 0}$ & 0,10 \\
\hline AQUEC_ELÉCTRICO & 0,31 & $-0,64$ & $-0,52$ & $-0,42$ & $-0,07$ \\
\hline AQUEC_GN & $-0,28$ & 0,66 & 0,52 & 0,35 & 0,16 \\
\hline AQUEC_BUTANO & 0,00 & $-0,10$ & 0,02 & 0,34 & $\mathbf{- 0 , 9 1}$ \\
\hline P_ALQUILER & $\mathbf{0 , 5 6}$ & $-0,29$ & 0,40 & $-0,01$ & 0,11 \\
\hline RENTA & $\mathbf{0 , 5 4}$ & 0,52 & 0,14 & $-0,04$ & 0,00 \\
\hline
\end{tabular}

Figura 1. Composición de los factores, matriz de componentes

\section{Análisis de conglomerados}

A partir estas siete variables y de sus 13 modalidades, el análisis de conglomerados jerárquicos agrupa los casos (las secciones censales) según los valores de cada componente obtenidos del análisis factorial. Se calcularon soluciones para agrupaciones de 2 a 5 conglomerados. La agrupación con mayor sentido era la que producía cuatro conglomerados, las otras soluciones han sido descartadas. Los rasgos de cada conglomerado, a partir de la comparación de las medias, resultan muy claros

5 La información estadística puede ser resumida por catorce ejes factoriales, pero solo los cinco primeros traducen una información significativa, llevando una parte de la varianza superando la media ( $10 \%$ de la inercia). 
y consistentes con las características materiales de las viviendas: el conglomerado 1 (17\% de las secciones censales) está caracterizado por la preponderancia de rentas altas y de altos niveles de equipos así como de aislamiento; los conglomerados 2,3 y 4 tienen valores inferiores de renta, con poca presencia de equipos térmicos (calefacción y aire acondicionado) y de medidas de aislamiento, y están diferenciados por los vectores energéticos utilizados así como por su edad y régimen de tenencia. Los perfiles de cada conglomerado se aprecian claramente en el gráfico de "caja de datos" siguiente, representando las diferencias de los valores medios de cada conglomerado (Figura 8). El eje de abscisas representa cuatro clases, y el eje de ordenadas, los valores tomados por las variables de $0 \%$ a $10 \%$, todos los datos siendo expresados en porcentaje a excepción del indicador de renta familiar, yendo de 0 a 250. La barra central representa la media, las extremidades de las cajas corresponden al primer y tercer cuartiles, y los extremos máximos de las líneas discontinuas están fijados al nivel de los valores máximos y mínimos. Los puntos adicionales encima de las cajas de datos representan secciones censales con valores extremos, descartadas del análisis para no distorsionar los resultados. Este gráfico toma sentido con la Figura 9, un mapa de Barcelona donde se han coloreado las secciones censales según la clasificación resultante del análisis.

La clase 1 totaliza el $17 \%$ de las secciones censales, y corresponde a zonas favorecidas del municipio, con un índice de renta bien superior a las tres otras clases. La presencia del aislamiento es más fuerte, con la mitad de las viviendas aisladas, por encima de las otras clases y el doble de la media del Municipio de 24\%. También son mayores la tasa de viviendas equipadas con climatización, así como la tasa de presencia de equipos de calefacción. Representadas en la Figura 9, estas secciones censales corresponden a dos subconjuntos. Uno de ellos se corresponde con la casi totalidad de los distritos de Sarriá, de Sant Gervasi, y del Eixample, la localización tradicional de los grupos altos a lo largo de la Diagonal (Rubiales et al. 2012). Las secciones censales del Oeste del distrito de Ciutat Vella también pertenecen a esta clase, y corresponden al barrio de Ciutat Vella que ha sido afectado por un proceso de gentrificación que ha impactado en la eficiencia energética (Ter Minassian 2013). Arquitectónicamente, este subconjunto corresponde a edificios construidos con principios arquitectónicos basados en amplias avenidas que permiten una mejor exposición al sol, grandes patios interiores garantizando circulaciones del aire y dando acceso a espacios verdes centrales. De hecho, el Pla Cerdà aprobado en 1855 creó las condiciones de un microclima progresivamente perdido con la presión urbanística del siglo XX. Las viviendas fueron divididas en pisos más pequeños, dañando la ventilación inicial que facilitaba una doble exposición (PECQ 2011). El segundo subconjunto corresponde a la zona del Front Maritim, producto de operaciones urbanas fruto de un modelo de gobernanza urbana bautizada como "modelo Barcelona" (Borja 2013). La eficiencia energética de esta zona litoral es el producto de operaciones inmobiliarias diseñadas para acoger los Juegos Olímpicos de Barcelona, creando nuevas centralidades en los barrios de Vila Olímpica y de Diagonal Mar. A esta política urbana se añade, desde los años 2000, una ambición por parte del 
ejecutivo municipal de hacer de la ciudad un escaparate de los compromisos de transición energética del Ayuntamiento, concretizada en la zona del "Fórum de las culturas" inaugurada en 2004. El principio director del proyecto, formulado por Vicente Guallart, entonces arquitecto jefe del Ayuntamiento, es el de la "ciudad autosuficiente" (Guallart 2012). Se traduce en la construcción de una amplia "pérgola solar" fotovoltaica, y por la instalación de una red de calor y de frio representada en la Figura 9.

La Clase 2 es una clase intermedia a la que corresponden $21 \%$ de las secciones censales, representada en color verde en las ilustraciones siguientes. Está caracterizada por una mayor penetración del gas natural para todos los usos, y un menor uso de la electricidad para calefacción y ACS que la media de las secciones del municipio. Esta clase corresponde a las zonas periféricas, donde el parque edificado es en parte un producto de la política de la ciudad en los años 1980, pero coincide también con una mezcla de clases socioeconómicas, explicando los valores medios alcanzados por el indicador de la renta. Al Norte del municipio, las secciones de esta clase corresponden tanto a los polígonos de Baró de Viver y de Bon Pastor - zonas desfavorecidas y alejadas de los grandes ejes de comunicación, sujetos de la política de inclusión social municipal desde los años 1980 (Ajuntament de Barcelona 2014) como a la reciente operación de urbanismo alrededor del centro comercial La Maquinista en Sant Andreu. Al Oeste, esta mezcla se repite: pertenecen a la Clase 2 a la vez secciones del distrito de Las Corts, que son el espejo de las nuevas centralidades en el extremo de la Diagonal, y secciones censales empobrecidas de Sants-Montjuïc, un distrito que presenta hoy indicadores de fuerte vulnerabilidad social. A pesar de sus diferencias, estas zonas se encuentran en el trayecto del eje del despliegue de la red de gas natural a partir del puerto de Barcelona.

La Clase 3 reúne el $36 \%$ de las secciones censales del municipio, y se caracteriza por una antigüedad de las viviendas que supera la media municipal, así como por una mayor presencia de equipos térmicos eléctricos - calefacción y calderas. El alquiler como régimen de ocupación es mayor, sin destacarse radicalmente del resto de la ciudad. Estas secciones corresponden al centro histórico, a la casi totalidad de los distritos de Ciutat Vella, de Sants Montjuic y de Gracia.

La Clase 4, con el $24 \%$ de las secciones, corresponde a los barrios más desfavorecidos y con un índice de renta inferior a la media municipal. Las instalaciones de calefacción y de climatización son escasas - en comparación con las otras clases. Otro elemento de diferenciación es la mayor presencia del butano para calentar las aguas sanitarias, con una media de las secciones donde entre $15 \%$ y $20 \%$ de las viviendas equipadas de calderas utilizan esta fuente de energía. La distribución espacial de la clase es homogénea, con una concentración en el Norte del municipio y en los distritos de Sant Andreu, de Nou Barris, de Horta-Guinardó y de Sant Martí. Coincide también con las operaciones de promoción de la vivienda protegida en el centro histórico desde los años 1980 (Ter Minassian 2013). 


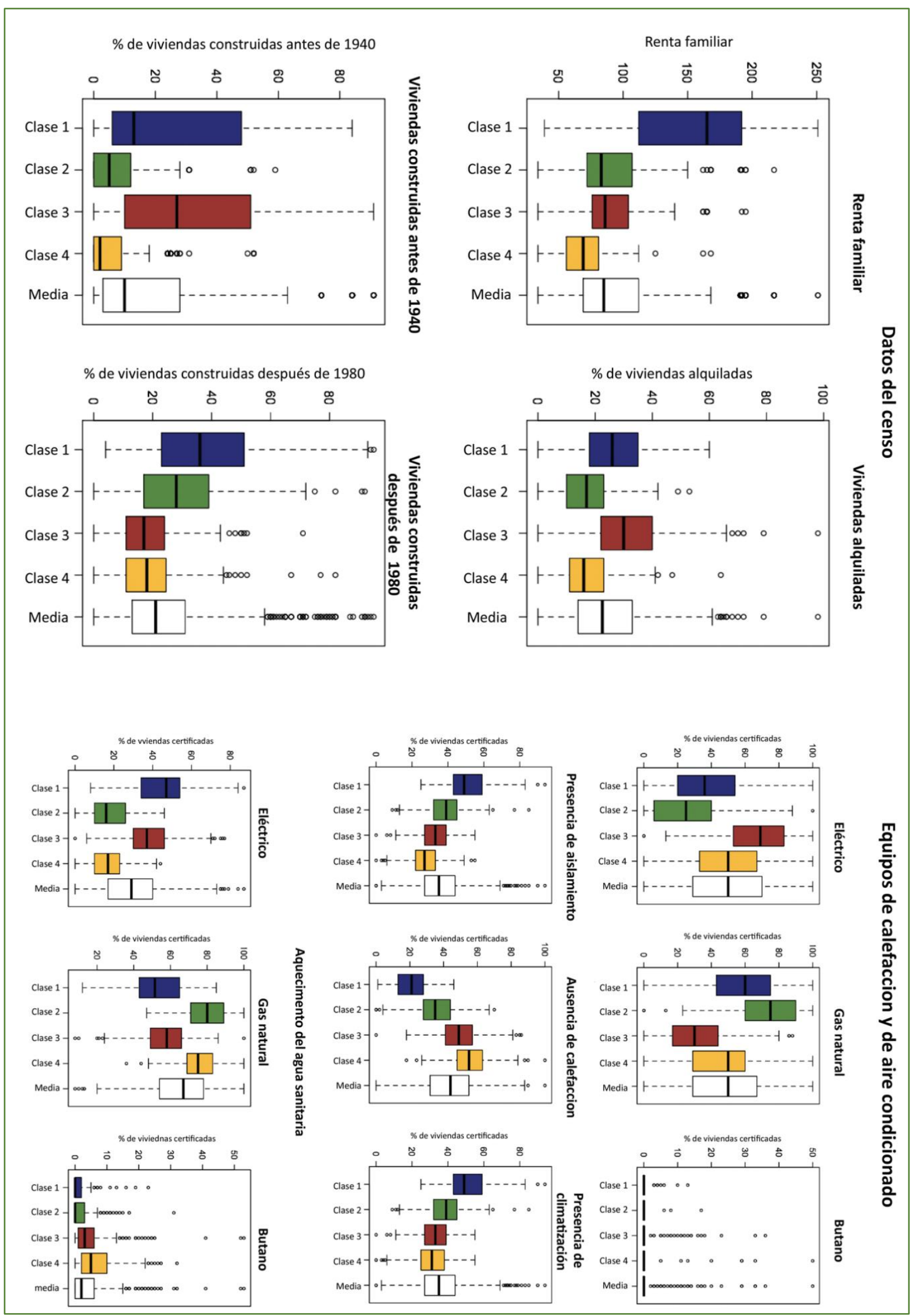

Figura 2. Caja de datos representando las diferencias de los valores de los conglomerados 


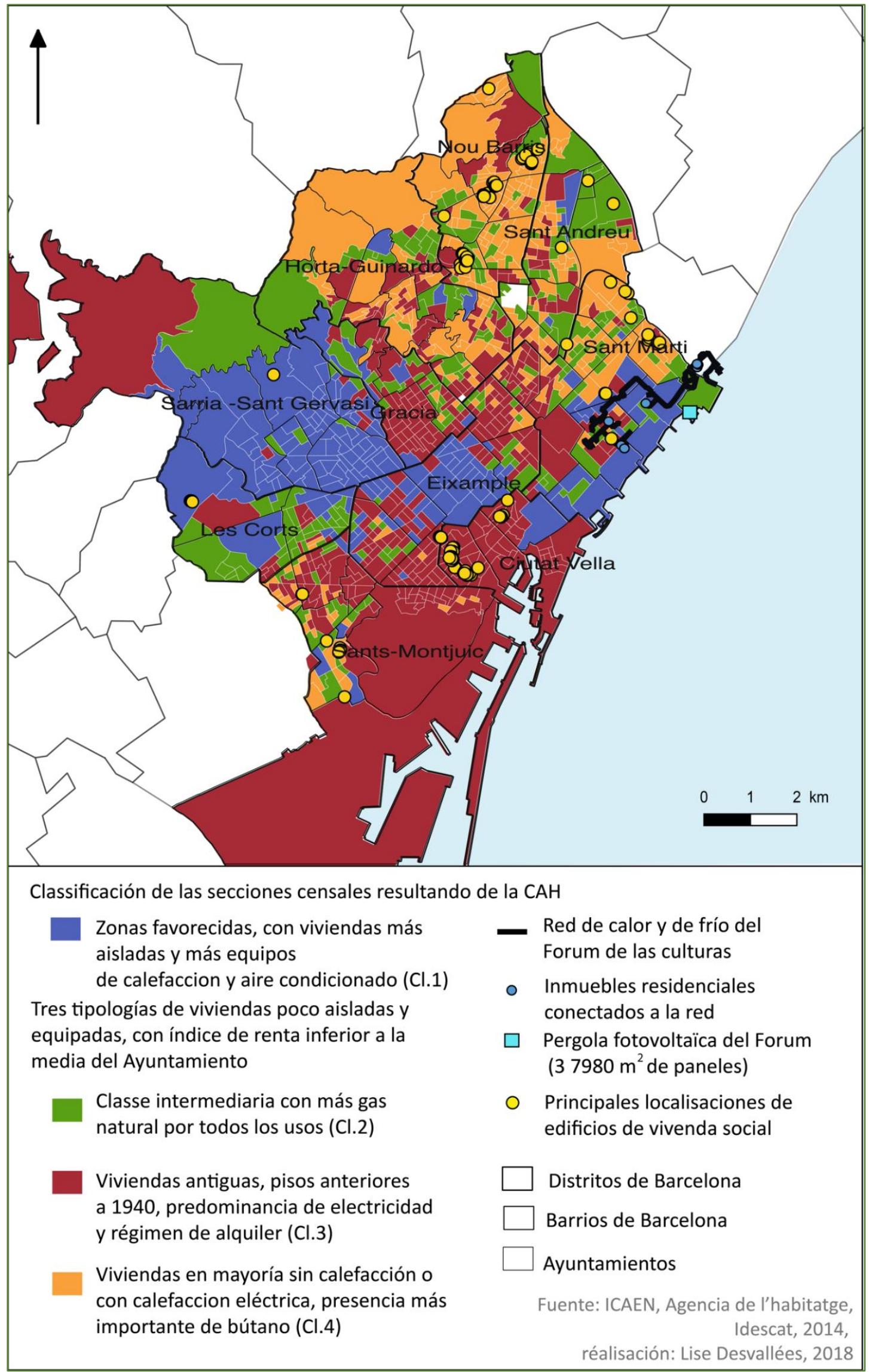

Figura 3. Mapa del análisis de conglomerados: los cuatro grupos de secciones censales en el Municipio 


\section{Conclusión}

Proponemos en esta conclusión una reflexión sobre la ambición de plantear una metodología robusta para cuantificar la vulnerabilidad energética a escala urbana, utilizando un enfoque contextualizado, indirecto y descentralizado.

En primer lugar, este enfoque permite identificar patrones espaciales finos de vulnerabilidad energética, gracias al uso de la información contextualizada de los certificados energéticos y del censo de población y viviendas. Los resultados muestran el carácter determinante de la renta en el aislamiento de las viviendas y en la tasa de equipos térmicos de calefacción y climatización de aire, apuntando a la existencia de secciones censales donde los habitantes pueden ser más vulnerables frente a las variaciones de temperatura. Los resultados permiten confrontar los discursos de las administraciones públicas locales con resultados estadísticos, y matizar las hipótesis derivadas de estos discursos, particularmente sobre las relaciones entre el tipo de vectores energéticos y las otras variables.

En el caso de la electricidad, conforme a los análisis existentes que vinculan la ineficiencia energética con el alquiler como régimen de ocupación (Sanz Fernández et al. 2017), observamos correlaciones en el centro histórico entre la ausencia de aislamiento y de equipos de calefacción o de climatización, las bajas rentas, y la presencia de calderas eléctricas. Este resultado apunta a una mayor vulnerabilidad de los habitantes del centro histórico frente a un aumento de los precios de la electricidad, con riesgo de privaciones más allá del confort térmico de inverno.

La geografía del gas natural coincide más con las fases sucesivas del desarrollo urbano de Barcelona que con las pautas espaciales de las rentas. El acceso a la red queda determinado por los obstáculos a su extensión y por las estrategias de renovación urbana del municipio de Barcelona. Estas áreas urbanas pueden presentar otro tipo de vulnerabilidad, cuando los gastos de electricidad se suman a los del gas natural y suponen una proporción importante de los ingresos domésticos.

El uso del butano corresponde a las dos lógicas de la pobreza socioeconómica y del desarrollo de la red de gas natural. De hecho, las bombonas de gas son más comunes en barrios situados en las zonas elevadas de la ciudad, donde la conexión a la red de gas natural es más compleja, pero también en zonas desfavorecidas de Sant Andreu, Nou Barris, Sant Marí, y Horta-Guinardó. Esta correlación sugiere que el uso de butano puede ser empleado como uno de los proxy para identificar áreas vulnerables a la pobreza energética.

Sin embargo, esta metodología presenta ciertos límites. Primero, los certificados energéticos no reflejan la totalidad de las viviendas, y su densidad varía en función del dinamismo del mercado inmobiliario, creando posibles distorsiones en la calidad de la información a la escala censal. Segundo, la ausencia de datos estadísticos sobre la renta a escala de las secciones censales, con el obligado recurso a un índice, es un déficit importante a la vista del carácter central de la variable en el análisis. Una posible solución podría ser la movilización de trabajos estadísticos que realizan aproximaciones de la renta a esta escala (Madariaga et al. 2011), con la futura publicación del censo de población y viviendas de 2021 . Tercero, el análisis estadístico 
solo tiene sentido cuando se articula con datos cualitativos recogidos previamente de los actores locales -sean las administraciones públicas, las organizaciones de la sociedad civil, o los hogares vulnerables - y las hipótesis necesitan una actualización constante.

A pesar de estas limitaciones, los resultados de este estudio pueden ser útiles en la emergente política municipal de mitigación de la pobreza energética para diferenciar pautas espaciales de la vulnerabilidad energética y destacar acciones prioritarias adaptadas a la variabilidad de los contextos infra urbanos.

\section{Bibliografía}

ACA. 2012. Informe: Pobreza energética en España, Potencial de generación de empleo derivado de la rehabilitación energética de viviendas. Madrid: Asociación de ciencias ambientales.

Disponible en: https://www.cienciasambientales.org.es/index.php/nuestralabor/estudios-y-guias

ACA. 2014. Informe: 2ndo Estudio Pobreza energética en España: análisis de tendencias. Madrid: Asociación de ciencias ambientales.

Disponible en: https://www.cienciasambientales.org.es/index.php/nuestralabor/estudios-y-guias

ACA. 2016. Informe: pobreza, vulnerabilidad y desigualdad energética. Nuevos enfoques de análisis. Madrid: Asociación de ciencias ambientales.

Disponible en: https://www.cienciasambientales.org.es/index.php/nuestralabor/estudios-y-guias

ACA. 2018. Informe: pobreza energética en España, hacia un sistema de indicadores y una estrategia de actuación estatales. Madrid: Asociación de ciencias ambientales. Disponible en: https://www.cienciasambientales.org.es/index.php/nuestralabor/estudios-y-guias

Ajuntament de Barcelona. 2014. Informe: estrategia de Desarrollo Urbano Sostenible e Integrado, Feder 2014-2020. Barcelona: Ayuntamiento de Barcelona Eje Besòs.

Ajuntament de Barcelona. 2017. Informe: Pla pel Dret a l'Habitatge de Barcelona 20162025. Barcelona: Regidoria d'Habitatge de l'Ajuntament de Barcelona.

Disponible en : https://habitatge.barcelona/ca/estrategia/pla-dret-habitatge

Ajuntament de Barcelona. 2020. Notas metodológicas: Distribución territorial de la renta familiar en Barcelona.

Disponible

en:

https://www.bcn.cat/estadistica/castella/dades/economia/renda/rdfamiliar/no tes/index.htm

Bayona i Carrasco, Jordi. 2007. “La segregación residencial de la población extranjera en Barcelona: ¿Una segregación fragmentada?". Scripta Nova 11 (235). Disponible

en:

http://revistes.ub.edu/index.php/ScriptaNova/article/view/1309 
Boardman, Brenda. 1991. Fuel poverty: from cold homes to affordable warmth. New Jers ey: John Wiley \& Sons Ltd.

Borja, Jordi. 2013. "Retour sur le "modèle Barcelone" par l'un de ses acteurs." En L'urbanisme Espagnol Depuis Les Années 1970. La Ville, La Démocratie, Le Marché, Coudroy de Lille, Lydia; Vaz, Céline; Vorms, Charlotte, 99-100, Presses universitaires de Rennes.

Bouzarovski, Stefan. 2014. "Energy poverty in the European Union: landscapes of vulnerability". Wiley Interdisciplinary Reviews Energy and Environment 3: 276289.

Bouzarovski, Stefan; Tirado Herrero, Sergio. 2015. “The energy divide: Integrating energy transitions, regional inequalities and poverty trends in the European Union." European Urban and Regional Studies 1 (18).

Bouzarovski, Stefan; Petrova, Saska. 2015. "A global perspective on domestic energy deprivation: Overcoming the energy poverty-fuel poverty binary". Energy Research and Social Science 10: 31-40.

Bouzarovski, Stefan; Tirado Herrero, Sergio; Petrova, Saska; Frankowski, Jan; Matoušek, Roman; Maltby, Tomas. 2017. "Multiple transformations: theorizing energy vulnerability as a socio-spatial phenomenon". Geografiska Annaler: Series B, Human Geography 99 ( 1).

Desvallees, Lise; Coutard, Olivier; Rutherford, Jonathan. 2020. "The politics of domestic energy vulnerability in the Barcelona region, between deconfinement and reconfinement." Geoforum 216, p. 201-210.

EFE. 2018. "" La Vanguardia.

Goñi Ros, Bernat. 2008. “Identificación, localización y caracterización de las secciones censales desfavorecidas de la región metropolitana de Barcelona. "Scripta Nova, XII (212). Disponible en :

http://revistes.ub.edu/index.php/ScriptaNova/article/view/1417

Gouveia, João Pedro; Seixas, Júlia. 2016. “Unraveling electricity consumption profiles in households through clusters: combining Smart meters and door-to-door surveys." Energy and buildings 116: 666-676.

Gouveia, João Pedro; Seixas, Júlia; Long, Gavin. 2018. "Mining household's energy data to disclose fuel poverty: lessons from Southern Europe." Journal of Cleaner Production 178: 534-550.

GUALLART, Vicente. 2012. La ciudad autosuficiente en red: Habitar en la sociedad de la información. RBA Libros.

ICAEN. 1989. Informe: Programa ESPREC. Barcelona: Institut Català d'Energía.

ICAEN. 2017. Informe: Observatori de l'estat energètic dels edificis a Catalunya. Barcelona: Institut Català d'Energía, Disponible en :

http://icaen.gencat.cat/ca/detalls/publicacio/Observatori-de-lestat-energetic-delsedificis-a-Catalunya-0000 1

Madariaga, Rafa; Martori, Joan Carles; Oller, Ramon. 2012. “Distribución espacial y desigualdad de la renta salarial en el área metropolitana de Barcelona." Scripta Nova XVI (405). Disponible en : http://www.ub.edu/geocrit/sn/sn-405.htm 
Martín-Consuegra, Fernando; Hernández Aja, Agustín; Oteiza, Ignacio; Alonso, Carmen. 2016. "Energy needs and vulnerability estimation at an urban scale for residential neighbourhoods heating in Madrid (Spain)." 2016. En Proceedings of plea 2016 Los Angeles - 32th International Conference on Passive and Low Energy Architecture 3: 1.413-1.419, Los Angeles, Ca. EEUU.

Martín-Consuegra, Fernando; Hernández Aja, Agustín; Oteiza, Ignacio; Alonso, Carmen. 2016. "Distribución de la pobreza energética en la ciudad de Madrid (España)". EURE (Santiago) 39 (135).

Ocaña Ocaña, Carmen. 2005. "Microanálisis sociodemográfico de espacios urbanos". Boletín de la Asociación Española de Geografia 40: 5-34. Disponible en: http://www.age-geografia.es/ojs/index.php/bage/article/view/2007

Pascual Pascuas, Ramón; Paoletti, Giulia; Lollini; Roberto. 2017. "Impact and reliability of EPCs in the real estate market." Energy procedia 140: 102-114.

PECQ. 2011. Informe: Pla d'energia, canvi climàtic i qualitat de l'aire de Barcelona. Barcelona: Ajuntament de Barcelona, Disponible en :

http://ajuntament.barcelona.cat/ecologiaurbana/sites/default/files/PlaEnergia_Canv iClimatic_QualitatAire-2011-2020.pdf

Rubiales Pérez, Miguel; Bayona-i-Carrasco, Jordi; Pujadas Rúbies, Isabel. 2012. "Patrones espaciales de la segregación residencial en la región metropolitana de Barcelona: pautas de segregación en los grupos altos." Scripta Nova XVI (423). Disponible en : http://www.ub.edu/geocrit/sn/sn-423.htm

Rowe, Peter G.; Ye Kan, Har. 2014. Urban Intensities: Contemporary Housing Types and Territories. Boston: Birkhauser.

Sanz Fernández, Ana, Gómez Muñoz, Gloria, Sánchez-Guevara Sánchez, Carmen, Núñez Peiró, Miguel. 2017. Informe: Estudio técnico sobre pobreza energética en la ciudad de Madrid. Ayuntamiento de Madrid. Disponible en:

https://www.ecologistasenaccion.org/wp-content/uploads/2019/01/estudiopobreza-energetica-madrid.pdf

Sareen, Siddarth, Thomson, Harriet, Tirado Herrero, Sergio, Gouveia, João Pedro, Lippert, Ingmar, Lis, Aleksandra. 2020. "European energy poverty metrics: scales, prospects and limits". Global Transitions 2: 26-36.

Ter Minassian, Hovig. 2013. "Les politiques urbaines municipales de la ville de Barcelone (1979-2008)". En L'urbanisme Espagnol Depuis Les Années 1970. La Ville, La Démocratie, Le Marché, editado por Coudroy de Lille, Lydia; Vaz, Céline; Vorms, Charlotte. Rennes: Presses universitaires de Rennes.

Tirado Herrero, Sergio; Ürge-Vorsatz, Diana. 2012. "Trapped in the heat: A postcommunist type of fuel poverty". Energy Policy 49: 60-68. Disponible en: 10.1016/j.enpol.2011.08.067 
(C) Copyright: Lise Desvallees, 2021

(c) Copyright: Scripta Nova, 2021.

Ficha bibliográfica:

DESVALLEES, Lise. Identificación, localización y caracterización de la vulnerabilidad energética a nivel de sección censal en el municipio de Barcelona Scripta Nova. Revista Electrónica de Geografía y Ciencias Sociales. Barcelona:

Universitat de Barcelona, vol. 25, Núm. 1 (2021), p. 293-263 [ISSN: 1138-9788]

DOI: $10.1344 / \operatorname{sn} 2021.25 .30257$ 
Anexo 1. Presentación de las variables utilizadas en el análisis multi-variable

\begin{tabular}{|c|c|c|c|}
\hline & Descriptivo de la variable & $\begin{array}{l}\text { Abreviación } \\
\text { utilizada en el } \\
\text { análisis }\end{array}$ & $\begin{array}{l}\text { Media y mediana } \\
\text { en el Ayunt. de } \\
\text { Barcelona }\end{array}$ \\
\hline \multirow{9}{*}{$\begin{array}{l}\text { Características de las } \\
\text { viviendas } \\
\text { Fuente: } \\
\text { ICAEN, certificación } \\
\text { energética 2013-2018 }\end{array}$} & $\begin{array}{l}\text { Porcentaje de viviendas con } \\
\text { aislamiento en el total de los } \\
\text { certificados en la sección }\end{array}$ & Aislamiento & $\begin{array}{l}\text { Media : } 24 \% \\
\text { Mediana : } 21 \%\end{array}$ \\
\hline & $\begin{array}{l}\text { Porcentaje de viviendas con aire } \\
\text { acondicionado en el total de los } \\
\text { certificados en la sección }\end{array}$ & Climatización & $\begin{array}{l}\text { Media : } 36 \% \\
\text { Mediana : } 35 \%\end{array}$ \\
\hline & $\begin{array}{l}\text { Porcentaje de viviendas sin } \\
\text { calefacción en el total de los } \\
\text { certificados en la sección }\end{array}$ & No_calefacción & $\begin{array}{l}\text { Media : } 42 \% \\
\text { Mediana : } 44 \% \\
\end{array}$ \\
\hline & $\begin{array}{l}\text { Porcentaje de viviendas con } \\
\text { Agua Caliente Sanitaria (ACS) } \\
\text { calentada con electricidad } \\
\end{array}$ & ACS_eléctrico & $\begin{array}{l}\text { Media :29\% } \\
\text { Mediana: } 29 \% \\
\end{array}$ \\
\hline & $\begin{array}{l}\text { Porcentaje de viviendas con Agua } \\
\text { Caliente Sanitaria (ACS) calentada } \\
\text { con gas natural }\end{array}$ & ACS_GN & $\begin{array}{l}\text { Media : } 65 \% \\
\text { Mediana : } 67 \%\end{array}$ \\
\hline & $\begin{array}{l}\text { Porcentaje de viviendas con Agua } \\
\text { Caliente Sanitaria (ACS) calentada } \\
\text { con gas de petróleo liquido }\end{array}$ & ACS_butano & $\begin{array}{l}\text { Media : } 4 \% \\
\text { Mediana : } 2 \%\end{array}$ \\
\hline & $\begin{array}{l}\text { Porcentaje del vector « electricidad » } \\
\text { viviendas con presencia de } \\
\text { calefacción }\end{array}$ & Aquec_eléctrico & $\begin{array}{l}\text { Media : } 49,5 \% \\
\text { Mediana :50\% }\end{array}$ \\
\hline & $\begin{array}{l}\text { Porcentaje del vector « gas natural » } \\
\text { viviendas con presencia de } \\
\text { calefacción }\end{array}$ & Aquec_GN & $\begin{array}{l}\text { Media : } 50 \% \\
\text { Mediana : } 50 \%\end{array}$ \\
\hline & $\begin{array}{l}\text { Porcentaje del vector « Gas de } \\
\text { petróleo liquido » en las viviendas } \\
\text { con presencia de calefacción }\end{array}$ & Aquec_butano & $\begin{array}{l}\text { Media : } 0,50 \% \\
\text { Mediana : } 0 \%\end{array}$ \\
\hline \begin{tabular}{|l} 
Renta de los hogares \\
Fuente: Ayuntamiento de \\
Barcelona, 2015 \\
\end{tabular} & $\begin{array}{l}\text { Índice de renta disponible } \\
\text { de los hogares }\end{array}$ & Renta & Índice : 100 \\
\hline $\begin{array}{l}\text { Régimen de propiedad } \\
\text { Fuente: Censo de } \\
\text { Población } \\
\text { y viviendas, } 2011\end{array}$ & Porcentaje de viviendas alquiladas & P_alquiler & $\begin{array}{l}\text { Media : } 24 \% \\
\text { Mediana : } 22 \%\end{array}$ \\
\hline $\begin{array}{l}\text { Edad de las viviendas } \\
\text { Fuente: Censo de }\end{array}$ & $\begin{array}{l}\text { Porcentaje de viviendas construidas } \\
\text { antes de } 1940\end{array}$ & Antes_1940 & $\begin{array}{l}\text { Media : } 19 \% \\
\text { Mediana : } 10 \%\end{array}$ \\
\hline $\begin{array}{l}\text { Población } \\
\text { y viviendas, } 2011\end{array}$ & $\begin{array}{l}\text { Porcentaje de viviendas construidas } \\
\text { después de } 1980\end{array}$ & Después_1980 & $\begin{array}{l}\text { Media : } 12 \% \\
\text { Mediana : } 10 \%\end{array}$ \\
\hline
\end{tabular}


